\title{
Reversible Atrioventricular Block and Junctional Ectopic Tachycardia in Coxsackievirus B3-Induced Fetal-Neonatal Myocarditis without Left Ventricular Dysfunction
}

\author{
Hironori Takahashi, M.D., ${ }^{1}$ Keiko Tsukamoto, M.D., ${ }^{1}$ Shigehiro Takahashi, M.D., ${ }^{1}$ \\ Tomoo Nakamura, M.D., Ph.D., ${ }^{1}$ Yushi Ito, M.D., Ph.D., 1 Masahide Kaneko, M.D.,2 \\ and Haruhiko Sago, M.D., Ph.D. ${ }^{1}$
}

We present a case of fetal-neonatal acute myocarditis caused by coxsackievirus B3 infection in a term neonate. The condition manifested as high-grade atrioventricular (A-V) block prenatally. After delivery, various arrhythmias such as high-grade A-V block, ventricular tachycardia, and junctional ectopic tachycardia appeared, and we had difficulty managing these arrhythmias. This is the first report describing a case of acute myocarditis due to coxsackievirus infection presenting with fetal $\mathrm{A}-\mathrm{V}$ block. This case is also unique in that it is extremely rare that various arrhythmias occur serially in one patient without left ventricular dysfunction.

KEYWORDS: Myocarditis, junctional ectopic tachycardia, fetal atrioventricular block, amiodarone hydrochloride

\section{CASE REPORT}

The patient was a newborn female delivered at 38 weeks' gestation to a 30 -year-old mother (gravid 1, para 1). The pregnancy course of the mother was uneventful. However, the infant had a 2-year-old sibling, who had had a rash and fever 8 days prior to the delivery. Her mother went to the hospital because she was worried about a decrease in fetal movement on the date of delivery. Fetal echocardiography showed high-grade atrioventricular $(\mathrm{A}-\mathrm{V})$ block, with a heart rate of 60 beats per minute.
Urgent cesarean section was performed, because of the nonreassuring fetal status. The newborn was relatively vigorous, weighing $3164 \mathrm{~g}$. Her Apgar score was 6 at 1 minute and 8 at 5 minutes. However, her heart rate was almost the same after delivery as before delivery. Mild subcutaneous edema and massive liver enlargement were noted on physical examination, but she had no fever. Her heart was significantly enlarged on chest radiograph (cardiothorax ratio 64\%). Echocardiography showed no structural abnormalities. The ejection fraction of the left
Departments of ${ }^{1}$ Maternal-Fetal and Neonatal Medicine and ${ }^{2}$ Medical Subspecialities, National Center for Child Health and Development, Setagaya-ku, Tokyo, Japan.

Address for correspondence and reprint requests: Hironori Takahashi, M.D., Department of Maternal-Fetal and Neonatal Medicine, National Center for Child Health and Development, 2-10-1 Okura, Setagaya-ku, Tokyo 157-8535, Japan (e-mail: hironori @alto.ocn. ne.jp).
Am J Perinatol Rep 2011;1:37-42. Copyright (C) 2011 by Thieme Medical Publishers, Inc., 333 Seventh Avenue, New York, NY 10001, USA. Tel: +1(212) 584-4662.

Received: December 15, 2010. Accepted after revision: March 4, 2011. Published online: April 11, 2011.

DOI: http://dx.doi.org/10.1055/s-0031-1277102.

ISSN 2157-6998. 


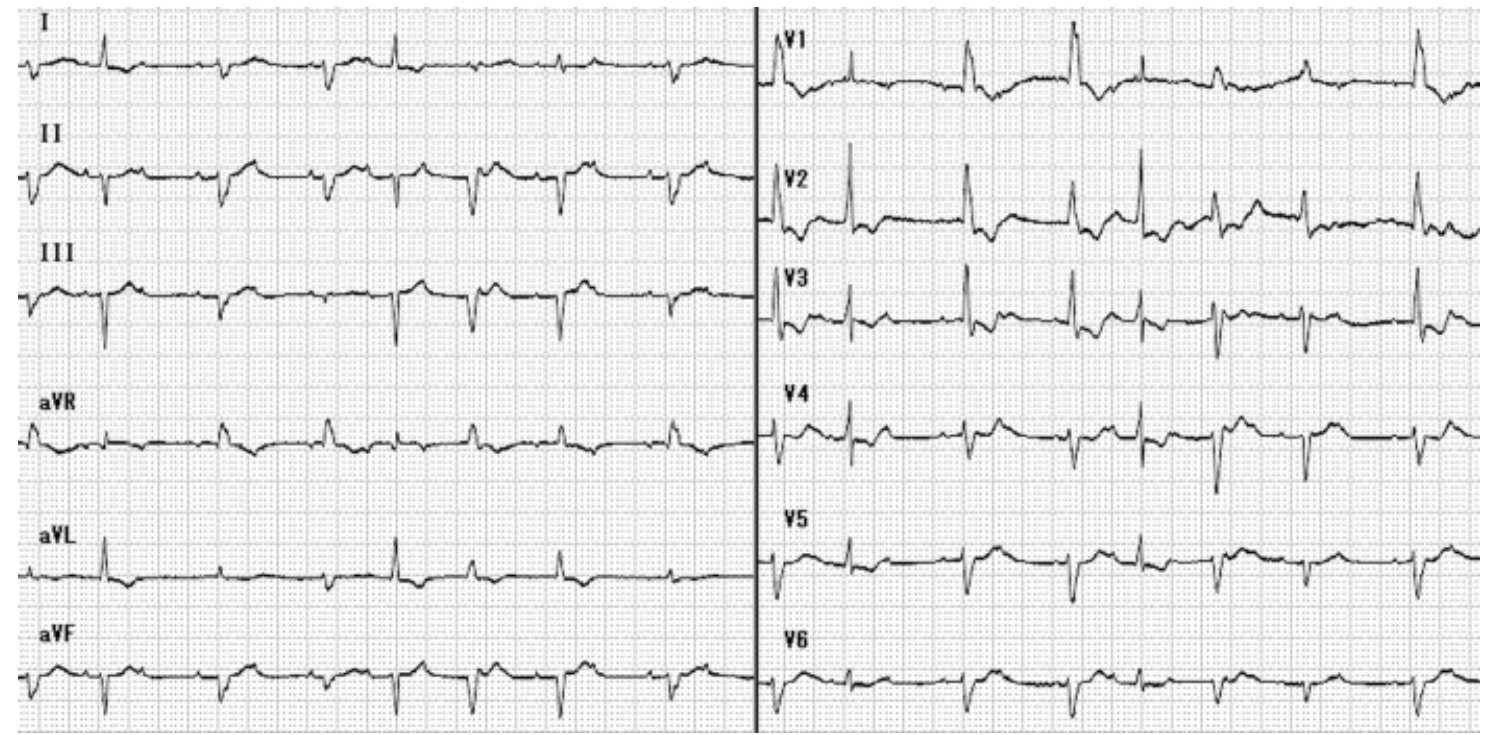

Figure 1 Atrioventricular block.

ventricle was $65 \%$; however, signs of right ventricular dysfunction, including right atrial dilatation, right ventricular dilatation, diminished contraction of the right ventricle, and a prolapsed tricuspid valve with moderate regurgitation, were present. Mild pericardial effusion and mild pleural effusion were also seen. Electrocardiography revealed high-grade $\mathrm{A}-\mathrm{V}$ block and premature ventricular contraction (Fig. 1). Initial laboratory values demonstrated a white blood cell count of 11,510 cells/ $\mathrm{mm}^{3}$, hemoglobin $11.5 \mathrm{~g} / \mathrm{dL}$, platelet count 241,000 cells $/ \mathrm{mm}^{3}$, aspartate transaminase $92 \mathrm{IU} / \mathrm{L}$, alanine transaminase $90 \mathrm{IU} / \mathrm{L}$, lactate dehydrogenase $1340 \mathrm{IU} /$ $\mathrm{L}$, brain natriuretic peptide (BNP) $8870 \mathrm{pg} / \mathrm{mL}$, and troponin T $2 \mathrm{ng} / \mathrm{mL}$. C-reactive protein was negative, and autoantibodies, including anti-Sjögren's syndrome A (SSA) antibody, were not detected.

After isoproterenol $(0.1 \mu \mathrm{g} / \mathrm{kg} / \mathrm{min})$ was administered intravenously, her heart rate increased to 90 beats per minute. On day 3 , her heart rate suddenly returned to within the normal range, and the high-grade $A-V$ block disappeared thereafter. Echocardiography showed obvious improvements in right ventricular function and prolapse of the tricuspid valve. BNP and troponin T levels were also dramatically decreased, to 409 and 0.39 $\mathrm{ng} / \mathrm{mL}$, respectively (Fig. 2). We suspected acute myocarditis and measured viral antibodies. Immunoglobulin $(1.0 \mathrm{~g} / \mathrm{kg} / \mathrm{d})$ was administered for 2 days. On day 4 , ventricular tachycardia was seen, which lasted for more than 1 minute; therefore, lidocaine hydrochloride (0.01 $\mu \mathrm{g} / \mathrm{kg} / \mathrm{min}$ ) was given instead of isoproterenol. Thereafter, the infant became stable. Her heart rate was in the range of 100 to 110 beats per minute, with first-degree A-V block.

On day 12, treatment with lidocaine hydrochloride was stopped. On the same day, junctional ectopic tachycardia (JET) occurred unexpectedly (Fig. 3).
Although propranolol ( 0.5 to $1.5 \mathrm{mg} / \mathrm{kg} / \mathrm{d}$ ) and adenosine $5^{\prime}$-triphosphate disodium ( 0.1 to $0.3 \mathrm{mg} / \mathrm{kg} / \mathrm{d}$ ) were added to the treatment, they were not effective. However, continuous amiodarone ( 5 to $7.5 \mathrm{mg} / \mathrm{kg} / \mathrm{d}$ ) infusion had a positive effect on JET. The paired serum concentration of coxsackievirus B3 rose more than fourfold from birth to day 21 (day 0: $4 \times$, day 21: $32 \times$ ). We diagnosed acute myocarditis caused by coxsackievirus B3 infection. The patient was discharged on day 39. Although the infant continues taking oral amiodarone $(5 \mathrm{mg} / \mathrm{kg} / \mathrm{d}$ ), she has developed normally. Her chest radiograph showed normal findings and her cardiac function was normal, without side effects or arrhythmias, at the 18th month.

\section{DISCUSSION}

Viral myocarditis in a neonate is a rare disease associated with various clinical findings. Neonatal myocarditis can be fatal in early infancy, as it tends to be more severe than that in childhood or adulthood. By using paired serum samples, we were able to identify that the causative virus of the myocarditis described in this case report was coxsackievirus B3. Although the immunoglobulin we administered could have affected the viral titer of her serum, we examined viral titers of the immunoglobulin we used and confirmed that coxsackievirus B3 was not elevated immediately after its administration. Bryant et al reported 10 cases of neonatal coxsackievirus B infection. ${ }^{1}$ According to the report, ${ }^{1}$ all infants had meningoencephalitis, four with myocarditis, two of whom died.

The most characteristic aspect of this case was that various arrhythmias were seen without obvious left ventricular dysfunction. Notably, there were three interesting points. First, myocarditis was discovered as a 


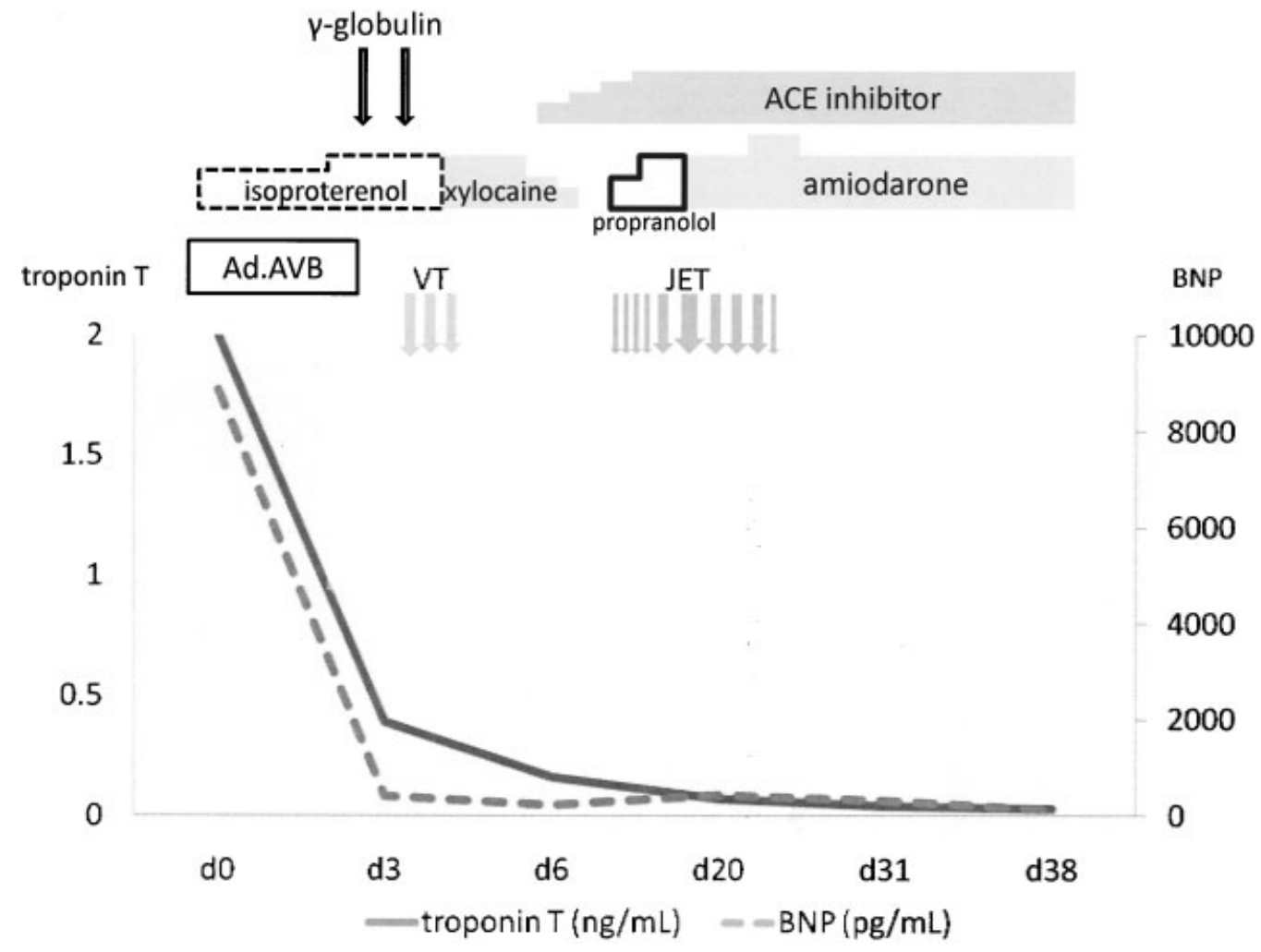

Figure 2 Clinical course. ACE, angiotensin-converting enzyme; as.AVB, advanced atrioventricular block; BNP, brain natriuretic peptide; JET, junctional ectopic tachycardia; VT, ventricular tachycardia.

result of fetal A-V block. To our knowledge, this is the first report describing that coxsackievirus $\mathrm{B}$-induced myocarditis manifested as fetal A-V block (Table 1). Fetal hydrops was previously considered the only finding observed in cases of unequivocal fetal infection. ${ }^{2}$ Although an old report described a case of fetal viral myocarditis discovered in an infant with $\mathrm{A}-\mathrm{V}$ block, ${ }^{3}$ the patient had autoantibodies against single-stranded DNA. Because anti-SSA antibodies are the primary reason for the development of fetal A-V block, the exact reason for the $A-V$ block observed in this old case is unknown. On the other hand, all autoantibodies we

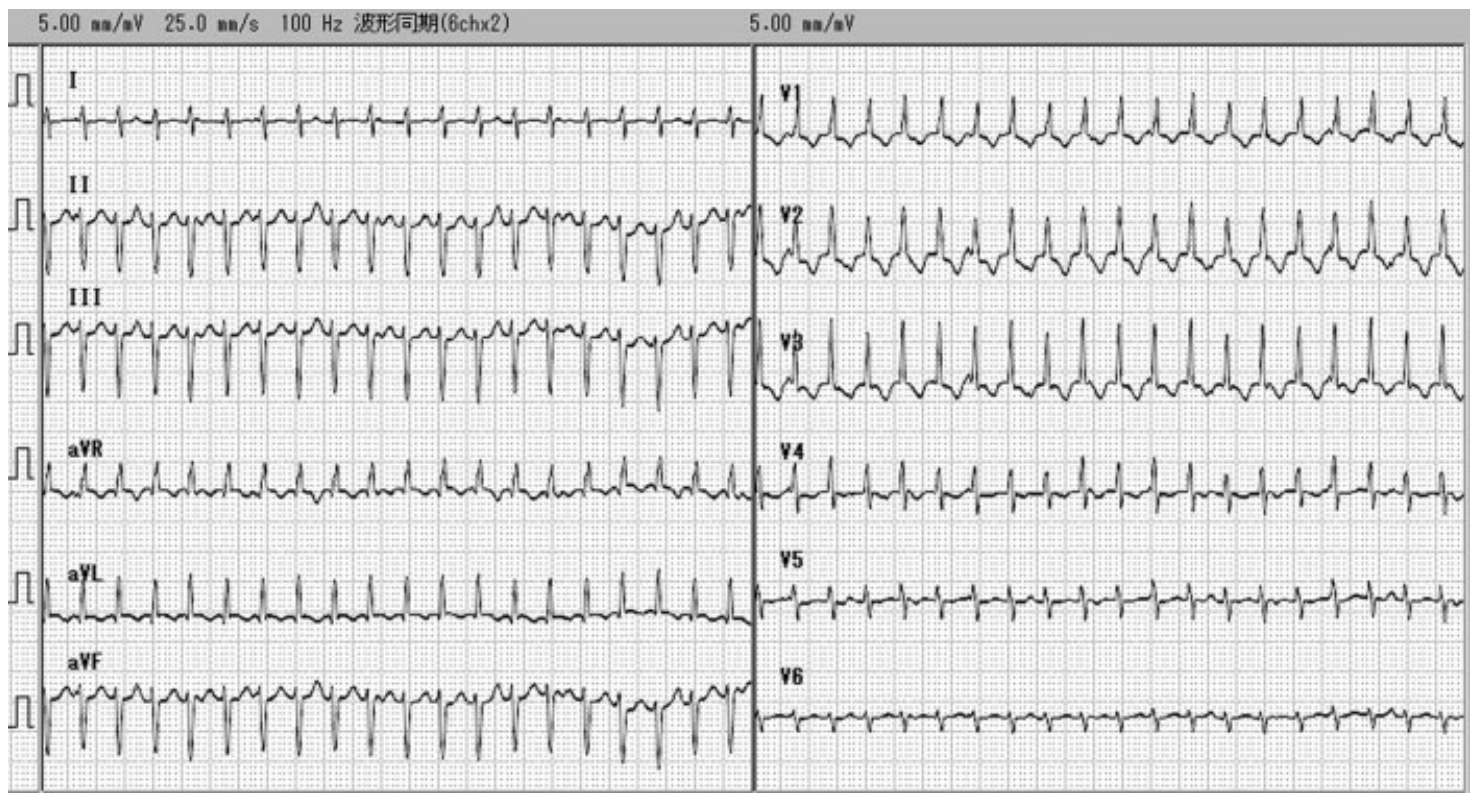

Figure 3 Junctional ectopic tachycardia. 


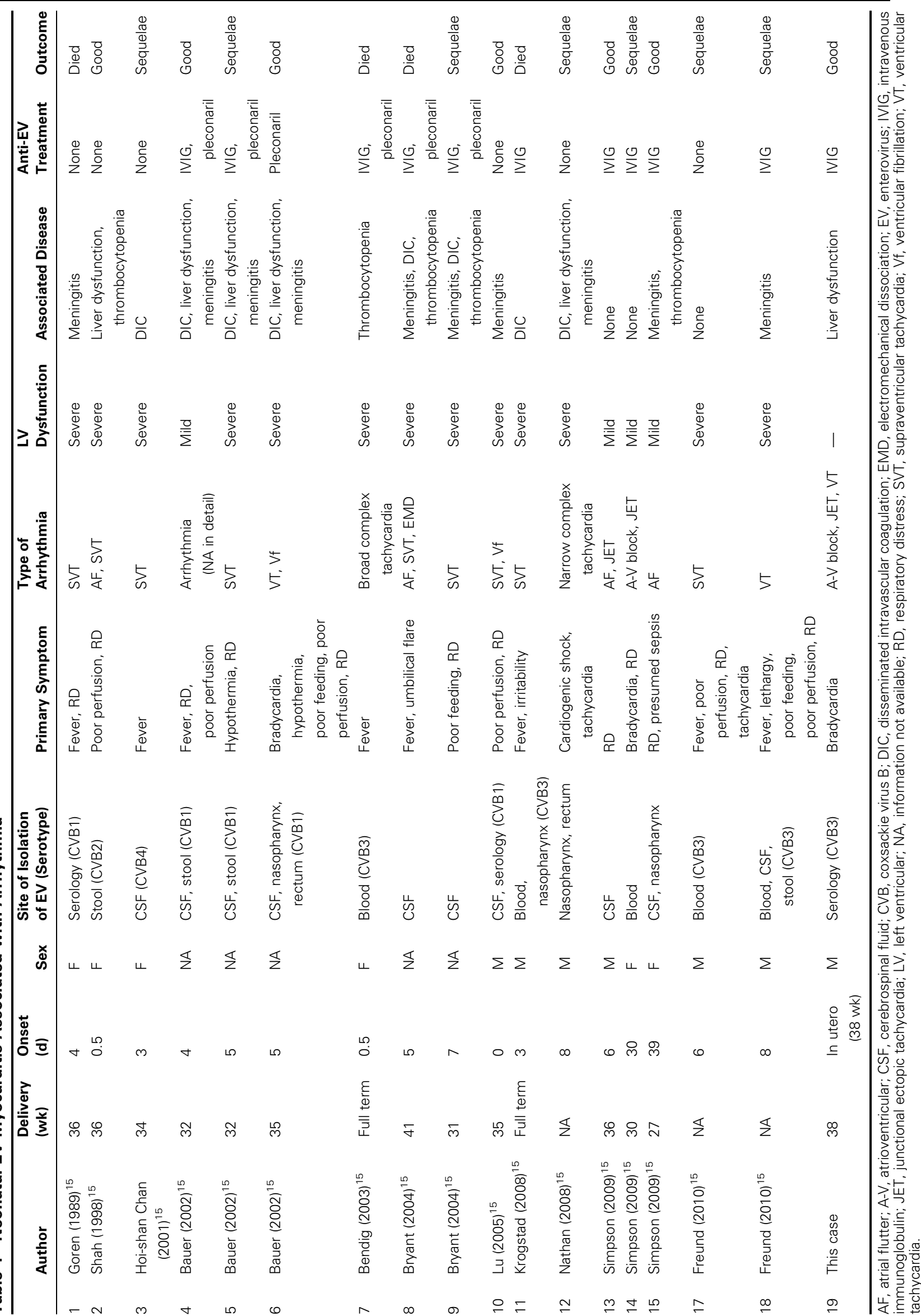


assessed were negative in the case described here, and we can therefore conclude that $\mathrm{A}-\mathrm{V}$ block likely occurred as a consequence of viral myocarditis. We also observed diverse electrocardiogram waveforms indicative of premature contractions and high-grade $\mathrm{A}-\mathrm{V}$ block. BNP and troponin $\mathrm{T}$ levels changed drastically, and right ventricular failure was observed. In addition, a change in the infant's serum coxsackievirus B3 titer was seen. For these reasons, we diagnosed acute viral myocarditis caused by transplacental coxsackievirus B3 infection.

Second, JET appeared on day 12, which we were able to control with amiodarone infusion. JET is a tachyarrhythmia that is generated by increased automaticity in an A-V junction. JET usually occurs after heart surgeries such as arterial switch operation, A-V canal repair, and Norwood repair. ${ }^{4}$ Otherwise, the occurrence of JET in the prenatal period is limited to the familial form. ${ }^{5}$ Usual arrhythmias associated with enterovirusinduced myocarditis include sinus tachycardia, supraventricular tachycardia, arterial flutter, ventricular tachycardia, and complete A-V block (Table 1). ${ }^{1,6-15}$ JET associated with neonatal viral myocarditis has only been reported twice. ${ }^{14,16}$ Although amiodarone is not an established therapy for neonates, we used amiodarone in accordance with a previous report. ${ }^{16}$ Treatment was very effective. Despite well-known side effects such as interstitial pneumonia and thyroid dysfunction, it appears from our results that amiodarone can be used safely in the neonatal period when these potential side effects are taken into account. In addition to JET, other arrhythmias such as ventricular tachycardia occurred in the case reported here. Thus, viral acute myocarditis due to enterovirus infection may cause life-threatening arrhythmias and circulatory collapse in neonates, ${ }^{17}$ which clinicians should respond to rapidly and adequately.

Third, the various arrhythmias, including $\mathrm{A}-\mathrm{V}$ block and JET, in the case presented were not accompanied by left ventricular dysfunction. Several previous reports have demonstrated an association between enterovirus myocarditis and left ventricular dysfunction, with resultant dilated cardiomyopathy. ${ }^{15,17}$ Most infants with enterovirus myocarditis were found to have accompanying left ventricular dysfunction and circulatory collapse, and their outcomes were poor. ${ }^{15,17}$ On the contrary, few neonatal case reports have described infants with neonatal enterovirus myocarditis with supraventricular arrhythmias that were not accompanied with serious left ventricular dysfunction. ${ }^{9,14}$ There is only one report describing a case very similar to ours, of an infant with viral myocarditis who had $\mathrm{A}-\mathrm{V}$ block and JET. ${ }^{16}$ Interestingly, the infant in this report also had no accompanying left ventricular dysfunction. However, a causative virus was not identified in this infant. In the case presented here, prominent depressed cardiac function, including prolapse of the tricuspid valve, was evident only in the right ventricle, not the left ventricle, during the period of $\mathrm{A}-\mathrm{V}$ block. The mechanism of right ventricular dysfunction is unclear, but coxsackievirus may initially have an affinity for the right atrium and ventricle, including the conducting systems. Moreover, in our case, the $\mathrm{A}-\mathrm{V}$ block and ventricular tachycardia were reversible. Enterovirus myocarditis without left ventricular dysfunction may thus be associated with only mild damage to the myocardium.

In conclusion, coxsackievirus B3-induced myocarditis should be considered when fetal A-V block or neonatal JET is observed. JET may occur in infants with coxsackievirus B3-induced myocarditis without left ventricular dysfunction. Although neonatal JET is resistant to several antiarrhythmic drugs, amiodarone is effective. We can use amiodarone safely in the neonatal period when its potential side effects are taken into account.

\section{REFERENCES}

1. Bryant PA, Tingay D, Dargaville PA, Starr M, Curtis N. Neonatal coxsackie B virus infection-a treatable disease? Eur J Pediatr 2004;163:223-228

2. Ouellet A, Sherlock R, Toye B, Fung KF. Antenatal diagnosis of intrauterine infection with coxsackievirus B3 associated with live birth. Infect Dis Obstet Gynecol 2004; $12: 23-26$

3. Repke JT, Kuhajda F, Hochberg MC, Johnson TR, Winn K, Provost T. Fetal viral myocarditis and congenital complete heart block in a pregnancy complicated by systemic lupus erythematosus. A case report. J Reprod Med 1987;32: 217-220

4. Batra AS, Chun DS, Johnson TR, et al. A prospective analysis of the incidence and risk factors associated with junctional ectopic tachycardia following surgery for congenital heart disease. Pediatr Cardiol 2006;27:51-55

5. Lupoglazoff JM, Denjoy I, Luton D, Magnier S, Azancot A. Prenatal diagnosis of a familial form of junctional ectopic tachycardia. Prenat Diagn 1999;19:767-770

6. Goren A, Kaplan M, Glaser J, Isacsohn M. Chronic neonatal coxsackie myocarditis. Arch Dis Child 1989;64:404-406

7. Shah SS, Hellenbrand WE, Gallagher PG. Atrial flutter complicating neonatal Coxsackie B2 myocarditis. Pediatr Cardiol 1998;19:185-186

8. Hoi-shan Chan S, Lun KS. Ventricular aneurysm complicating neonatal coxsackie B4 myocarditis. Pediatr Cardiol 2001; 22:247-249

9. Bauer S, Gottesman G, Sirota L, Litmanovitz I, Ashkenazi S, Levi I. Severe Coxsackie virus B infection in preterm newborns treated with pleconaril. Eur J Pediatr 2002;161: 491-493

10. Bendig JW, Franklin OM, Hebden AK, et al. Coxsackievirus B3 sequences in the blood of a neonate with congenital myocarditis, plus serological evidence of maternal infection. J Med Virol 2003;70:606-609

11. Lu JC, Koay KW, Ramers CB, Milazzo AS. Neonate with coxsackie B1 infection, cardiomyopathy and arrhythmias. J Natl Med Assoc 2005;97:1028-1030

12. Krogstad P, Hammon R, Halnon N, Whitton JL. Fatal neonatal myocarditis caused by a recombinant human enterovirus-B variant. Pediatr Infect Dis J 2008;27:668-669 
13. Nathan M, Walsh R, Hardin JT, et al. Enteroviral sepsis and ischemic cardiomyopathy in a neonate: case report and review of literature. ASAIO J 2008;54:554-555

14. Simpson KE, Hulse E, Carlson K. Atrial tachyarrhythmias in neonatal enterovirus myocarditis. Pediatr Cardiol 2009;30: 827-830

15. Freund MW, Kleinveld G, Krediet TG, van Loon AM, Verboon-Maciolek MA. Prognosis for neonates with enter- ovirus myocarditis. Arch Dis Child Fetal Neonatal Ed 2010;95:F206-F212

16. Maiers JA, Ebenroth ES. Junctional ectopic tachycardia following complete heart block associated with viral myocarditis. Pediatr Cardiol 2006;27:367-368

17. Inwald D, Franklin O, Cubitt D, Peters M, Goldman A, Burch M. Enterovirus myocarditis as a cause of neonatal collapse. Arch Dis Child Fetal Neonatal Ed 2004;89:F461-F462 